\title{
IMPLEMENTATION OF SCIENTIFIC RESOURCES WITH USE SELF-AUDIT IN GENERAL EDUCATIONAL SCHOOLS
}

\author{
Ilhama Asadova \\ Institute of Education of the Republic of Azerbaijan, Department of Economics \\ and Management of Education, senior research fellow \\ E-mail: i.esedova@arti.edu.az \\ https://orcid.org/0000-0003-1570-0192
}

\begin{abstract}
The article reflects the issue of the implementation of scientific resources through self-study in secondary schools. Detection of delays in self-education schools, identifying the causes of failures, and developing recommendations are characterized as the most important method of serving the democratization of internal control. The article also provides an overview of scientific and pedagogical management resources. In pedagogical management, the system of scientific values is presented at school as values that integrate such important factors as modernization, communication, dynamic development, sustainability, intrinsic motivation, initiative and creativity. The implementation of academic resources through the use of self-auditing in schools is based on the transformation of the results obtained during self-audit to the school's overall frontal activity. World practice has consistently noted that new management values, new methods, teaching resources, uniform curricula, textbooks and their diversity and diversity have increased, and therefore modernization in all areas needs radical improvement of our pedagogical values.
\end{abstract}

Keywords: self-audit, scientific resource, pedagogical management, values, quality, suggestion, recommendation, standard, international experience, curriculum.

\section{DOI:}

To cite this article: Asadova I. (2021). Implementation of scientific resources with use self-audit in general educational schools. Journal of Preschool and Primary Education, Vol. 237, Issue IV, pp. 45-58

Article history: received - 02.12.2021; accepted - 15.12.2021. 


\title{
ORTA ÜMUMTOHSIL MOKTӘBLORINDӘ ÖZÜNÜAUDITDӘN İSTİFADӘ YOLU İLO ELMİ RESURSLARIN REALLAŞDIRILMASI
}

\author{
İlhamə Osədova \\ Azərbaycan Respublikası Təhsil İnstitutu, \\ Təhsilin iqtisadiyyatı və menecmenti şöbəsinin böyük elmi işçisi \\ E-mail: i.esedova@arti.edu.az \\ https://orcid.org/0000-0003-1570-0192
}

\begin{abstract}
Annotasiya. Məqalədə ümumtəhsil məktəblərində özünüauditin formalaşdırılması, nəzarətin müasir metodlarla həyata keçirilməsi və elmi-intellektual resurs bazası yaratmaqla keyfiyyətin yüksəldilməsi barədə məlumat verilir. Pedaqoji idarəetmədə elmi dəyərlər sistemi, məktəblərin müasirləşdirilməsi, ünsiyyət, dinamik inkişaf, davamlılıq, daxili motivasiya, təşəbbüs və yaradıcılıq nümayiş etdirilməsi kimi mühüm amilləri özündə birləşdirən dəyərlər kimi təqdim olunur. Qeyd olunur ki, dünya təcrübəsində vaxtaşırı yeni idarəetmə dəyərlərinə, yeni metodlara, tədris resurslarına, vahid kurikulumlara, dərsliklərə, onların müxtəlifliyinin və rəngarəngliyinin artırılmasına ehtiyac var və buna görə də pedaqoji dəyərlərimizin bütün sahələrdə müasirləşdirilməsinin köklü surətdə təkmilləşdirilməsi tələb olunur.
\end{abstract}

Açar sözlər: özünüaudit, elmi resurslar, pedaqoji idarəetmə, dəyərlər, keyfiyyət, təklif, tövsiyə, standart, beynəlxalq təcrübə, kurikulum.

\section{DOI:}

Məqaləyə istinad: Эsədova İ. (2021). Orta ümumtəhsil məktəblərində özünüauditdən istifadə yolu ilə elmi resursların reallaşdırılması. «Məktəbəqədər və ibtidai təhsil», № 4 (237), səh. 45-58

Məqalə tarixçəsi: göndərilib - 02.12.2021; qəbul edilib - 15.12.2021. 


\title{
РЕАЛИЗАЦИЯ НАУЧНЫХ РЕСУРСОВ С ИСПОЛЬЗОВАНИЕМ САМОАУДИТА В ОБЩЕОБРАЗОВАТЕЛЬНЫХ ШКОЛАХ
}

\author{
Ильхама Асадова \\ Старший научный сотрудник отдела экономики и \\ менеджмента образования Института Образования \\ Азербайджанской Республики \\ E-mail: i.esedova@arti.edu.az \\ https://orcid.org/0000-0003-1570-0192
}

\begin{abstract}
Аннотация. В статье рассказывается о формировании самоаудита в общеобразовательных школах, управлении контролем современными методами и повышении качества путем создания научно-интеллектуальной базы ресурсов. В педагогическом управлении система научных ценностей представлена как ценность, объединяющая такие важные факторы, как модернизация школы, коммуникация, динамическое развитие, устойчивость, внутренняя мотивация, демонстрация инициативности и творчества. В мировой практике периодически отмечается, что имеется потребность в новых управленческих ценностях, новых методах, учебных ресурсах, единых учебных программах, в учебниках и повышении их разнообразия и красочности и, следовательно, модернизация во всех областях требует радикального улучшения наших педагогических ценностей.

Ключевые слова: самоаудит, научный ресурс, педагогическое управление, ценности, качество, предложение, рекомендация, стандарт, международный опыт, учебная программа.
\end{abstract}

\section{DOI:}

Ссылка на статью: Асадова И. (2021). Реализация научных ресурсов с использованием Самоаудита в общеобразовательных школах. «Дошкольное и началное оброзование», № 4 (237), стр. 45-58

История статьи: поступила - 02.12.2021; принято - 15.12.2021. 


\section{Введение / Introduction}

Образование является одним из областей, составляющих основу динамического развития общества. Как и во всех областях, так и в сфере образования, управление служит решающим этапом на пути повышения качества. Поскольку основы образования закладываются в общеобразовательных учреждениях, они всегда находятся в центре внимания государства и общества. Одним из ведущих направлений управления в общеобразовательных школах является организация контроля. «Несмотря на то, что выполнение этой задачи, в основном, является обязанностью руководства школы, велико его значение и в повышении показателей качества общественного контроля. И это является методом самоаудита управления государственно-общественного характера» [Qəribov Ş., 2018]. Иными словами, новый подход к внутреннему контролю в управлении.

\section{Основная часть / Main part}

Самоаудит является важным направлением, ориентированным на подход государственно-общественного характера, на управление школой. Конечной целью самоаудита является улучшение качества и в целом, повышение рейтинга школы. «При контроле должна быть создана такая система, при которой сотрудник учреждения не пытался бы скрыть то, чего он не знает и не умеет, напротив, он должен полагаться на поддержку учителей и менторов»

[Терехов А. А., 2008]. Необходимо добиться того, чтобы сотрудники стремились к участию в тренингах, а не уклонялись от них. Одним из способов достижения этого развития является внедрение самоаудита.

«Самоаудит, будучи одним из элементов контроля управления, представляет собой процесс достижения поставленных учреждением целей и задач» [Әhmədov A., Abbasov Ә., 2013]. Исследование текущей ситуации, согласование поставленных стандартов с реальными результатами, внесение необходимых корректировок, принятие опережающих и дополнительных мер являются одним из функций самоаудита.

«Под организацией управления в общеобразовательных школах предусматривается весь организационный процесс, осуществляемый руководством внутри школы» [Mәmmədzadə R., 2010]. Ведущая роль директора в управлении состоит в том, чтобы он, координируя прогнозированный план 
деятельности управляемой им школы согласно алгоритму, направил бы его на управление коллективом. Основная задача руководства школы состоит в подборе и размещении кадров, в предпочтении общественных задач, с соблюдением регулярного дневного режима среди педагогического коллектива, в активизации творческих объединений учащихся, поддержании стабильной педагогической и психологической среды и в создании условий для обеспечения высокой деловитости. Орган по самоаудиту школы смог организовать работу, описанную выше.

Самоаудит в общеобразовательных школах, будучи методической деятельностью, в качестве системы базового элемента контроля управления, состоит из различных разделов [Әhmədov A., Abbasov Ә., 2013]. Самоаудит, как новый метод повествует о методологической деятельности управления. «Самоаудит, охватывая все сферы деятельности школы, будучи совокупностью ревизионных дел, понимается как самоконтроль, самооценивание и определение собственного рейтинга» [Овсянко Д.В., 2011]. Самоаудит является наиболее важным методом выявления недостатков в образовании, определения причин неудач, подготовки предложений и оказания помощи в демократизации внутреннего контроля. Цель самоаудита - добиться повышения качества, оказать помощь учителям, при использовании инноваций и новейших методов в педагогическом процессе, детально изучить и проанализировать текущую ситуацию. Применение самоаудита в школах повышает эффективность учебно-воспитательного процесса, укрепляет отношения с родителями и государственными организациями, а также повышает качество учебного процесса в целом.

Деятельность школьного педагогического коллектива, осуществление контроля внутри школы и организация внутришкольного самоаудита являются наилучшими способами достижения высоких результатов. Внутришкольный самоаудит - это модернизированный метод демократического контроля, основанный на научных принципах учебного процесса и международного опыта. В течении одного учебного года целесообразно применять самоаудит в три этапа. Первый этап проводится в форме изучения существующего положения (диагностического), второй - полугодового, третий - годового исследования. «Первый этап проводится в диагностической форме в начале учебного года для изучения реального положения. Второй этап проводится в первой половине учебного года с рекомендациями по осуществлению запланированных по областям задач, выявлению допущенных недостатков и разработке профилактических мер по своевременному устранению отставания. На данном этапе определяется динамика развития. Третий этап проводится либо по завершении поставленной 


\section{http://ppe-journal.edu.az}

цели, либо по окончании учебного года» [Әhmədov A., Abbasov Ә., 2013]. А это измерение и оценивание результатов годовой деятельности школы. С другой стороны, это - этап проведения сравнения между установлением стандартов и реальным положением и подготовки отчета итоговых результатов учебного года. Данный этап самоаудита позволяет руководителям школ сравнивать достигнутые результаты с установленными стандартами, принимать решения, составлять план деятельности на следующий учебный год, основываясь на прогнозирования и новшества образования, а также позволяет разработать отчеты вышестоящим органам исполнительной власти.

Важно принять во внимание ряд аспектов для организации самоаудита. Здесь обязательно уместное использование методов контроля. Это наряду с проведением самоаудита, являющегося одним из вариантов внутреннего контроля, важно и с точки зрения получения объективных результатов и принятия решений и предложений [https://www.google.ru/search?caмоаудит]. Планирование предстоящих работ, с учетом текущей ситуации и установленных стандартов, оперативный контроль выполняемой работы и учет результатов являются одним из способов повышения качества образования. Проведенные эксперименты показывают, что самоаудит в общеобразовательных школах охватывает все сферы школьной деятельности. «Самоаудит обеспечивает максимальное выполнение задач, поставленных перед школой и выдвинутых в директивах и нормативно-правовых документах, устраняет отставания, повышает эффективность обучения и воспитания, служит удовлетворению потребностей заказчиков образования и повышению качества образования» [Güneş H., 2016]. С другой стороны, применение самоаудита в общеобразовательных школах облегчает реализацию научных ресурсов.

При внедрении в общеобразовательных школах самоаудита за основу берется реализация научных ресурсов. Научный ресурс является вспомогательным средством. Ресурсами считаются: существующие резервные базы в любой области, доступные к использованию средства, возможности и потенциальные источники. В образовательных учреждениях, научные ресурсы, служащие для удовлетворения потребностей, могут быть материальными и не материальными. Научные ресурсы в основном являются нематериальными. Созданные опытными специалистами научные ресурсы хранятся на определенных носителях и передаются с их помощью. В современный период обеспечение ресурсами, в основном, организовано в электронной форме. Обеспечение научными ресурсами классифицируется в соответствии с действующими законами, образованием и статистикой.

При внедрении самоаудита в общеобразовательных школах важно со- 
здать электронную научно-интеллектуальную базу учреждения. В настоящее время одним из основных требований современной науки является создание таких баз. Создание электронной научно-интеллектуальной базы самоаудита и более надежное хранение и защита данных научных ресурсов в будущем, повышает возможности школьного контроля и расширяет творческую сферу. Актуальна необходимость формирования в школах единой электронной научно-интеллектуальной базы.

Электронные ресурсы хранятся в соответствии с базовой системой каждой школы, что позволяет систематизировать электронные ресурсы в едином формате и легко обмениваться существующей научной информацией. Международный опыт показывает, что основу успеха составляет наличие в школах научно-интеллектуальной базы и связь этих баз с всемирно известными научными базами. Создание единой системы электронного управления в школах позволяет регулировать деятельность этого процесса в целом и формировать современный контроль, тем самым подчеркивая важность актуальности самоаудита.

Школы, внедряющие самоаудит, также могут сравнивать свои работы по показателям качества и в регионах. В этом случае школа с легкостью может определить свой рейтинг. «Школа, определив научно-аналитическую информацию о текущем положении, получает возможность построить свою деятельность на основе новых критериев» [Serdal İ., 2017]. Школа сможет расширить свою базу обеспечения научных ресурсов, сравнивая свои статистические и аналитические показатели с показателями предыдущих лет.

Под ресурсами общеобразовательной школы подразумеваются все потенциальные ресурсы, служащие целям организации и управления деятельностью школы. Для реализации плана деятельности школы согласно требованиям Государственных образовательных стандартов, следует определить цель деятельности школы, организацию и управление работой в указанном направлении [Azərbaycan Respublikasında təhsilin inkişafı üzrə Dövlət Strategiyas1, 2013]. Научные ресурсы включают в себя материально-техническую базу школы, научные кадры, электронные варианты или планы мастер-классов, документацию методических объединений, статьи педагогических работников, учебные пособия, методические рекомендации и другие образцы. Наряду с этим, они также могут включать электронную информацию, методические пособия, электронные учебные ресурсы и ресурсы по отдельным занятиям. К ним также относятся инструкционные книги, предназначенные для развития обучения, по различным разделам и использованию методологий, учебные пособия для несовершеннолетних и начинающих, художественные произведения для общего использования и 


\section{http://ppe-journal.edu.az}

издания популярных классических и современных произведений в сокращенном формате. В научные ресурсы также входит реализация существующего законодательства в области человеческих ресурсов органами управления образованием и образовательными учреждениями, а также руководство научным управлением.

Анализируя и оценивая по отдельным направлениям деятельность органа самоаудита, с точки зрения контроля над управлением школой, руководствуются указами, распоряжениями и нормативными документами министерства образования, уставом, конституцией страны, законами «Об образовании», «О доступе к информации, «О библиотечном деле». «Одной из функций самоаудита является реализация системы обеспечения внутришкольными научно-материальными ресурсами» [Тихолоз А. С., 2014]. Это один из алгоритмов, который включает в себя эффективность и последовательность методологической деятельности при самоаудите. В методической деятельности самоаудита важно соблюдение эффективности и последовательности. Для активности методической деятельности требуется:

- рекомендации по обеспечению учителей различными методическими программами;

- создание базы данных по границам уровней;

- определение профессиональной пригодности для каждой области;

- уточнение направлений;

- способы устранения проблем;

- поддержка развития мотивации для лучшего функционирования школы;

-повышение эффективности в направлении реализации системы обеспечения внутришкольных научно-материальных ресурсов.

Самоаудит, проводимый в такой последовательности, определяет и осуществляет направление реализации научных ресурсов школы. Создается возможность широкого использования инноваций в управлении для активности методической деятельности. «Чтобы овладеть комплексом поставленных задач, управляющие должны обладать профессиональной компетентностью» [Güneş H., 2016]. Соответственно, образовательные услуги, предоставляемые руководителями коллективу должны быть на высоком уровне. Изучение методологической деятельности определяется по практическим направлениям. Методическая деятельность самоаудита раскрывает активность механизмов реализации. Здесь исследуются практикумы, открытые уроки, проекты, ход мероприятий и т. д., а также изучаются результаты, одобряются достижения и даются рекомендации по устранению отставаний. 
В управлении, в конечном итоге, оцениваются все области деятельности самоаудита. «Посредством самоаудита анализируются и проясняются уклонения от запланированных процессов, отставания и причины их возникновения, результаты деятельности управляющих» [Терехов А. А., 2008]. Тем не менее, поскольку преобразование результатов в ценности является одной из основных целей, прилагаются усилия для перевода в ценности результатов, полученных по многим направлениям. В центре внимания находятся усилия по достижению систематического внедрения законов, принципов и функций, полученных в результате самоаудита. В данном случае предусматривается систематизировать правила и принципы качества, динамическое развитие, формирование лидерских качеств и определение степени достижения целей в соответствии со стандартами. Ведутся поиски способов преобразования в ценности ресурсов, удовлетворяющих потребности учащихся, создание уровня координации, обеспечение родительского объединения, учет ответственности, среды, процессов, креативности в содержании, обучающих и обучаемых.

Проверка, проведенная на основе самоаудита позволяет объективно определить образовательную деятельность обучающих [http://2.abatskobr. ru/ru/samoaudit-shkoly/]. Изучение в полном объеме знаний, умений и навыков, необходимых для учащихся, раскрывается общественным аудитором. Используя этот вариант, исследуются результаты общей деятельности школы по каждому направлению. С целью устранения возникающих в школе недостатков, управляющим предоставляются рекомендации и предложения самоаудита. Ответственные стороны, для устранения отставаний, на основе рекомендаций и предложений самоаудита разрабатвают план мероприятий и контролируют их выполнение. «При самоаудите в центре внимания находится процесс оценивания обучения, уровень соответствия обучаемых определенным стандартам, показатели результатов диагностики, прояснение динамического развития, участии в олимпиадах, соревнованиях и конкурсах по отдельным предметам» [Mehmet K., 2010]. Результаты, полученные в результате организации самоаудита для исследования фронтальной деятельности школы в целом влияют на:

- положение координации действий, выполняемых в школе;

- влияние происходящих изменений на качество;

- возможность реализации выгодных возможностей;

- развитие обмена информацией;

- положение оптимального распределения управления школой;

- организация процесса контроля над деятельностью школы;

- уточнение результатов большого суммативного оценивания достиже- 


\section{http://ppe-journal.edu.az}

ний учащихся;

- результаты качества решения поставленных проблем.

В процессе самоаудита целесообразно преобразовать эти результаты в ценности.

Самоаудит является одной из современных моделей системы внутреннего контроля. Создание и внедрение самоаудита в образовании способствует повышению качества, совершенствованию системы управления, вносит предложения в соответствующие органы управления, стремится улучшить качество. «На диагностическом этапе самоаудит изучает текущее состояние, отслеживает динамическое развитие качества полугодовых и итоговых этапов, дает рекомендации и предложения с целью устранить недостатки и отставания, а также предлагает преобразовать результаты в ценности» [Чувашова Л. В., 2004]. Выполняет функции управления государственно-общественного характера и помогает устранить недостатки и отставания, допущенные до внешнего аудита. Осуществление всех этих мероприятий способствует воспитанию здорового поколения. Это также служит цели создания здорового общества и сохранения этой среды, формированию новых ценностей. Данная задача, стоящая перед государством, учебно-воспитательными учреждениями и семьей, всегда находится в центре внимания. Эта работа, которая начинается с адаптации детей из разных семей к одинаковому режиму обучения и коллективу, продолжается в плановом порядке и на основе принципа преемственности служит цели формирования ребенка как личности. «Повышение динамики качества начинается с эффективной организации управленческой деятельности и формирования профессионального коллектива в учреждениях» [Беглова Т. Б., Белова А. В., Битянова М. Р., 2011]. Это ставит на передний план систему ценностей в педагогическом управлении, состоящем из синтеза педагогических, методических и управленческих ценностей.

Система научных ценностей в педагогическом управлении представляет собой ценности, объединяющие в себе такие важные факторы, как модернизация учреждения, коммуникацию, динамическое развитие, устойчивость, отношения, доверие, внутреннюю мотивацию, демонстрацию инициативности и креативности. Исследования показывают, что обучение и воспитание на основе ценностей более эффективное, чем образование, основанное на цифрах. Иными словами, неправильно ограничивать развитие потенциальных возможностей детей лишь в направлении на получение высшего образования в будущем. «Для превращения приобретенных детьми знаний в навыки, параллельно с развитием существующих потенциалов и формированием новых умений и навыков, целью должно стать развитие 
их существующего потенциала характера и создание новых положительных характеров» [Әliyev P., 2017]. Для этого, в первую очередь, важно, чтобы управляющие учебными заведениями обладали ценностями педагогического управления и руководствовали современными механизмами системы ценностей.

Общеобразовательная школа - это период первичного формирования общественной жизни. Основным условием этой сферы является развитие интеллектуального и творческого потенциала, а также подготовка достойных гражданскому обществу индивидуумов. В школах требуется учебно-воспитательная работа, решение теоретических и практических вопросов, развитие демократии, прав человека, свободы, социальных структур и форм управления. Управляющие школой несут ответственность перед государством, общественностью, родителями и учениками за защиту прав детей, организацию их качественной и эффективной работы.

В последнее время формируется новая система ценностей управления различного характера. «Создание модернизированной системы ценностей в управлении образованием, ценности из международного опыта невольно влияют на сознание людей, обновляются отношения к образованию» [Ağayev Ә., 2015]. В духовной жизни общества с каждым днем возрастает роль науки и культуры. Усваиваются значения прогностических, научных исследований.

Идеи проектирования будущей жизни на основе научно-методических идей приводят к изменению отношения людей к жизни. «В мировой практике последовательно растет внимание к новым управленческим ценностям, новым методам, учебным ресурсам, единым учебным программам, учебникам и их разнообразию» [Әsədova İ., 2016]. По этой причине имеется потребность в проведении модернизации во всех сферах, а также в совершенствовании наших педагогических ценностей. Целью является овладение учащимися знаниями, умениями и логическим мышлением, которые обеспечат ему существование в будущей жизни.

«Система ценностей педагогического управления наряду с обоснованностью на международном опыте, также сформирована с учетом специфических особенностей сферы образования» [Mehrabov A., 2007]. В данную систему ценностей входят: достоинство, этика, качество, социальная ответственность, конкуренция, обмен, свобода. Основной целью стратегии, определяющей основные задачи системы образования, является создание компетентным учителям такой системы ценностей в образовании, которая бы занимала передовую позицию среди стран мира по результатам качества, обширности и обладала бы инфраструктурой, основанной на новей- 


\section{http://ppe-journal.edu.az}

ших технологиях.

Нормы, влияющие на поведение в процессе управления человеческими ресурсами, и их роль в управлении основаны на этических кодексах. Подходы, используемые для принятия решений, являются сложными с этической точки зрения и неразрывно связаны с принципами управления, ценностями и этическими нормами. Усовершенствование этического поведения, обновление этических систем управления принимаются на основе совокупности принципов управления этики. В педагогическом управлении этические стандарты нашли свое отражение в рамках закона. Законные рамки у каждого управляющего школой, за минимальную обязательную основу берут поведенческие стандарты и принципы. «Это один из основных ценностей усиливающих этическое поведение. От управляющих и управляемых требуется уважать эти ценности. Управление условиями и человеческими ресурсами в педагогическом управлении направляют этическое поведение» [Рывкин Е.Ю., 2014].

\section{Заключение / Conclusion}

Одной из главных областей реформ в сфере управления образованием является определение путей внедрения системы ценностей. В управлении образованием такие вопросы как четкое определение системы отношений между участниками и функций органов регулирования, точное выявление их полномочий и ответственности, повышение ответственности за результаты образования и полномочий управления образовательными учреждениями, мониторинг и оценивание деятельности, а также усовершенствование системы показателей, измеряющих качество образования, нашли свое решение в процессе самоаудита. В связи с разработкой нормативно-правовых документов в общеобразовательных школах, велись наблюдения за делами и проводились социальные опросы с руководителями школ. Были изучены документы, исследованы и проанализированы организация работ по управлению и контролю в школах. Полученные с помощью математического и статистического метода результаты уточнены, а ценности обобщены. Проведен анализ педагогической, методической литературы, статей, порталов, веб-сайтов с использованием теоретического анализа и получены соответствующие результаты.

Актуальность статьи. Повышение качества образования в общеобразовательных школах создает потребность реализации научных ресурсов. Эти потребности требуют формирования новых управленческих ценностей и актуализирует внедрение самоаудита как современного метода контроля. 
Научная новизна статьи. Самоаудит обеспечивает максимальное выполнение задач, поставленных перед школой и выдвинутых в директивах и нормативно-правовых документах, устраняет отставания, повышает эффективность обучения и воспитания, служит удовлетворению потребностей заказчиков образования и повышению качества образования. С другой стороны, применение самоаудита в общеобразовательных школах облегчает реализацию научных ресурсов.

Практическая значимость статьи. Одним из целей педагогического управления является достижение реализации системы обеспечения внутришкольными научно-материальными ресурсами. Внедрение самоаудита как современного варианта контроля в общеобразовательных школах имеет практическое значение с точки зрения как изучения фронтальной деятельности в целом, так и наряду с преобразованием полученных результатов в ценности, реализации научных ресурсов.

\section{Список использованной литературы / References}

1. Azərbaycan Respublikasında təhsilin inkişafı üzrə Dövlət Strategiyası. (2013). 24 oktyabr, 2013-cü il tarixli, 13 nömrəli Sərəncamla təsdiq edilmişdir. Bak1, "Azərbaycan müəllimi".

2. Ağayev Ә. (2015). Təlim prosesi: ənənə və müasirlik. Bak1, "Mütərcim”, s. 138

3. Ohmədov A., Abbasov Ә. (2013). Ümumi təhsildə inteqrasiya: müasir yanaşmalar. "Azərbaycan müəllimi”, 10 may.

4. Oliyev P. (2017). Ümumtəhsil məktəblərinin təlim-tərbiyə işləri üzrə direktor müavinlərinin fəaliyyətinin modernləşdirilməsi. Ümumtəhsil məktəblərinin idarə edilməsinin modernləşdirilməsi. Bakı, "Vahid MMC", s. $8-128$.

5. Әsədova İ. (2016). Ümumtəhsil müəssisələrinin idarə olunmasında özünüauditdən istifadə. Bak1, "Hacıŏlu E" MMC, $80 \mathrm{~s}$.

6. Mehrabov A. (2007). Müasir təhsilin konseptual problemləri. Bak1, "Mütərcim", 448 s.

7. Məmmədzadə R. (2010). Təhsildə keyfiyyət aparıcı istiqamətlərdən biri kimi. Bak1, "Müəllim", 170 s.

8. Qəribov Ş. (2018).Ümumtəhsil məktəblərində kollegial idaerəetmə fəaliyyətinin təşkili. Təhsilin idarə edilməsinə yeni yanaşma. Bakı, "Mütərcim", s. 144-196.

9. Qəribov Ş., Đsədova İ. (2018). Təhsilin sistemli idarə olunması (ümumtəh- 


\section{http://ppe-journal.edu.az}

sil məktəbləri əsasında). Bakı, "Hacığlu - E" MMC, 228 s.

10. Güneş H. (2016). Eğitim yönetimi. Ankara, "Nobel Akademi”, $160 \mathrm{~s}$.

11. Mehmet K. (2010). Çağdaş denetim yaklaşımları. Elazı̆̆, Fırat Üniversitesi, Sosyal Bilimler, № 2, s.181-200.

12. Serdal I.(2017). Eğitimde toplam kalite yönetimi uygulamaları. İstanbul, Hiperlink, $396 \mathrm{~s}$.

13. Беглова Т. Б., Белова А. В., Битянова М. Р. (2011). Школьный самооаудит. Материалы по критериям и технологиям самообследования школы. М.: «Педагогический поиск», 144 с.

14. Овсянко Д. В. (2011). Управление качеством. Издательство «Высшая школа менеджмента», $204 \mathrm{c}$.

15. Рывкин Е.Ю.(2014).Самоаудит, как основа управления методической деятельностью. Волгоград, издательства «Учитель».

16. «Самоаудит в дошкольном образовательном учреждении». (2014). (Теоретический материал к ГМО подготовлен заведующим МДОУ дोс комбинированного вида № 12 «Жемчужина» Ждановой Л.В., 26 апреля, 2014).

17. Тихолоз А. С. (2014). Самоаудит классного руководителя. 2014/2015 учебный год.http://nsportal.ru/nachalnaya-shkola/materialy-mo/201.

18. Чувашова Л. В. (2004). Аудит и самоаудит профессиональной деятельности педагога. (Краевой центр образования) «Практика административной работы в школе», №1, с.10-17.

19. Терехов А. А. (2008). Контроль и аудит. М.: «Финансы и статистика», $208 \mathrm{c}$.

20. http://2.abatskobr.ru/ru/samoaudit-shkoly/

21. https://www.google.ru/search?самоаудит. 